\title{
Deteksi Kerusakan Batang Rotor pada Motor Induksi Menggunakan Analisis Arus Mula Berbasis Hilbert Transform
}

\author{
Istiqomah, Dimas Anton Asfani, dan Dedet Candra Riawan \\ Jurusan Teknik Elektro, Fakultas Teknologi Industri, Institut Teknologi Sepuluh Nopember (ITS) \\ Jl. Arief Rahman Hakim, Surabaya 60111 \\ E-mail: istiqomah12@mhs.ee.its.ac.id, anton@ee.its.ac.id, dedet@ee.its.ac.id
}

\begin{abstract}
Abstrak - Kerusakan batang rotor merupakan salah satu jenis kerusakan pada motor induksi yang dapat menyebabkan masalah serius. Kerusakan tersebut dapat mencapai 5\% - 10\% dari seluruh kasus gangguan motor induksi. Oleh karena itu, perlu adanya diagnosis awal yang mendeteksi adanya gangguan pada rotor motor induksi, agar dapat dilakukan perbaikan lebih cepat dan tanggap sebelum terjadi gangguan yang lebih besar.

Tugas Akhir ini membahas terkait teknik deteksi kerusakan batang rotor pada motor induksi dengan menggunakan analisis arus mula. Sistem yang digunakan berbasis decomposition wavelet transform terlebih dahulu kemudian dilanjutkan dengan analisis berbasis hilbert transform sebagai perangkat pengolahan sinyal sehingga mampu mendeteksi motor dalam keadaan sehat atau mengalami kerusakan.

Pengujian sistem dilakukan dalam beberapa kondisi, yaitu kondisi tanpa beban dan berbeban. Selain itu, kondisi yang diberikan adalah kecacatan mulai dai 1BRB hingga 3BRB. Hasil pengujian membuktikan bahwa decomposition wavelet transform dan Hilbert transform mampu mendeteksi perbedaan kondisi pada motor induksi normal ataupun rusak pada batang rotor.
\end{abstract}

Kata Kunci- Motor Induksi, Keruskan Batang Rotor, Decomposition Wavelet Transform, Hilbert Transform.

\section{PENDAHULUAN}

$\mathrm{M}$ OTOR induksi merupakan peralatan yang sering digunakan pada proses operasi di industri. Hal ini disebabkan oleh motor induksi memiliki banyak keunggulan. Adapun kelebihan motor induksi adalah konstruksi yang lebih sederhana, kehandalan yang lebih tinggi, biaya yang relatif lebih murah dibandingkan motor jenis lain, perawatannya mudah, tidak memerlukan motor lain untuk starting awal. Tetapi disamping itu, motor induksi juga memiliki kekurangan, diantanya adalah sulitnya pengaturan putaran motor agar mempunyai kecepatan dan frekuensi yang konstan dan memiliki arus starting yang cukup tinggi sekitar lima sampai enam kali arus nominal motor. Disamping hal tersebut, motor induksi adakalanya mengalami kerusakan sehingga menyebabkan operasi harus dihentikan. Hal ini tentu saja dapat merugikan perusahaan dalam bentuk finansial, tenaga dan waktu dikarenakan akan mempengaruhi proses produksi industri tersebut. Beberapa gangguan yang sering merusak motor induksi rotor antara lain, kerusakan bearing, gangguan pada air gap, dan patah atau terkikisnya batang rotor.

Kerusakan batang rotor motor induksi mencapai 5\% - 10\% dari seluruh kasus gangguan motor induksi [1]. Beberapa hal yang dapat menyebabkan kerusakan batang rotor motor induksi antara lain : adanya tingkat pemanasan yang sangat parah, adanya gesekan dan benturan saat proses perawatan motor, proses manufaktur motor yang kurang sempurna, dan lain sebagainya [2]. Gangguan ini tentunya akan merugikan industri. Selain itu arus mula yang cukup besar ketika awal mula motor induksi beroperasi dapat pula sebagai penyebab kerusakan motor induksi. Oleh karena itu, perlu adanya diagnosa awal yang mendeteksi adanya gangguan pada rotor motor induksi, agar langkah perbaikan lebih cepat dan tanggap sebelum terjadi gangguan yang lebih besar.

Pedektesian kerusakan batang rotor motor induksi telah banyak dilakukan dengan beberapa cara,antara lain: tingkat vibrasi motor, temperature mesin, adanya arus urutan nol, serta perubahan daya dan faktor daya secara cepat. Namun dari beberapa cara yang telah ada membutuhkan biaya yang cukup besar. Dalam tugas akhir ini akan membahas mengenai sistem deteksi kerusakan batang rotor motor induksi dengan analisis arus mula berbasis Hilbert Transform. Pada pengerjaan tugas akhir ini akan dilakukan proses dekomposisi pada transformasi wavelet untuk selanjutnya hasil sinyal tersebut dapat dilihat perbedaan kondisi dalam keadaan batang rotor sehat maupun rusak dengan melihat jumlah ripple yang dihasilkan. Selain itu, untuk metode transformasi hilbert, yaitu dilakukan penyederhanaan sinyal dengan sistem interpolasi pada salah satu sinyal hasil dekomposisi untuk dapat melihat hasil perbedaan nilai puncak pada kondisi batang rotor dalam keadaan normal atau mengalami kerusakan.

\section{DETEKSI KERUSAKAN BATANG ROTOR PADA MOTOR INDUKSI}

\section{A. Konsep Wavelet}

Transformasi wavelet adalah sebuah transformasi matematika yang digunakan untuk menganalisis sinyal bergerak. Metode Transformasi berbasis wavelet merupakan salah satu cara untuk dapat digunakan untuk menganalisis sinyal-sinyal non-stasioner. Metode ini juga digunakan untuk mendeteksi kejadian-kejadian tertentu serta dapat digunakan untuk pemampatan data [4]. Selain itu, Transformasi wavelet juga dapat digunakan untuk analisis sinyal-sinyal nonstasioner (yaitu sinyal yang kandungan frekuensi bervariasi terhadap waktu), karena berkaitan dengan kemampuannya untuk memisah-misahkan berbagai macam karakteristik pada berbagai skala [4]. Kelebihan dari analisi sinyal menggunkan 
wavelet adalah bahwa dapat dipelajari karakteristik sinyal secara lokal dan detail, sesuai dengan skala yang dimiliki.

DWT dapat mengubah sinyal sumber menjadi dua klasisfikasi sinyal, yaitu sinyal dengan frekuensi tinggi dengan resolusi waktu yang tinggi dan frekuensi renda dengan resolusi waktu yang tinggi. Sinyal ini bekerja pada dua filterisasi DWT, yaitu highpass filter dan lowpass filter agar frekuensi dari sinyal tersebut dapat dianalisis. Setelah melewati proses filterisasi, dilanjutkan dengan operasi subsampling dengan mengambil masing-masing setengah dari keluaran filter. Proses tersebut disebut dengan proses dekompisisi. Proses dekomposisi dapat dilakukan secara berlanjut dengan memperhatikan level yang digunakan, hingga menghasilkan tingkatan dekomposisi yang sesuai.

\section{B. Hilbert Transform}

Dalam teknik analisis data telah ditemukan suatu metode oleh N.E Huang, yaitu transformasi Hilbert. Berbeda dengan transformasi fourier, transformasi Hilbert lebih berupa algoritma (pendekatan empiris) yang dapat diaplikasikan ke kumpulan data. Transformasi Hilbert merupakan fungsi yang menggeser fase pada suatu sinyal sebesar $\pm \pi / 2$. Transformasi Hilbert dapat pula disebut sebagai all pass filter. Transformasi Hilbert hanya menggeser fase sinyal dan tidak mengubah spectrum amplitude dari sinyal. Tujuan dari transformasi ini adalah untuk menghasilkan sinyal imajiner dari sinyal nyata. Sinyal nyata, yaitu $i(t)$ dapat ditunjukkan pada instantaneous amplitude (IA) adalah sebagai berikut:

$i(t)=A(t) \cdot \cos (\varnothing(t))$

Dengan nilai $A(t)$ dan $\varnothing(t)$, yaitu

$A(t)=\left[x^{2}(t)+y^{2}(t)^{1 / 2}\right.$

$\emptyset(t)=\arctan x(t) / y(t)$

Nilai $A(t)$ merupakan nilai nilai envelope atau disebut juga nilai amplitude sesaat (instantaneous amplitude), sedangkan untuk $\emptyset(t)$ disebut dengan fase sesaat (instantaneous phase) yang merupakan sudut yang terbentuk antara komponen riil dan imajiner.

Pada instantaneous amplitude dapat dilakukan beberapa langkah untuk dapat mengklasifikasikan fungsi tersebut. Salah satu langkah yang dapat menjelaskan algoritma ini adalah dengan menggunakan interpolasi. Fungsi ini digunakan untuk mempermudah pengelompokan sinyal dalam kondisi motor sehat maupun rusak. Dari hasil interpolasi akan menghasilkan pendekatan sinyal hingga menjadi fungsi sederhana.

\section{PERANCANGAn Sistem DeteKsi KerUSAKAN}

\section{A. Konfigurasi Sistem}

Sistem pada tugas akhir ini menggunakan analisis arus mula berbasis Hilbert Transform. Pengujian yang dilakukan berdasarkan pada pengambilan arus mula (starting) pada batang rotor motor induksi. Pengujian sistem ini membutuhkan beberapa peralatan, antara lain adalah motor induksi tiga-fasa, generator sinkron, beberapa buah lampu, Analog to Digital Converter berupa suatu module yang terdiri dari cDAQ-9171 dan NI 9215, power analyzer, mesin bor, kunci, obeng, palu, tang, serta seperangkat listing pengolahan sinyal dalam sebuah software terprogram. Gambaran sistem deteksi kerusakan batang rotor pada motor induksi berbasis
Hilbert Transform pada Tugas Akhir ini secara sederhana ditunjukkan pada gambar 1.

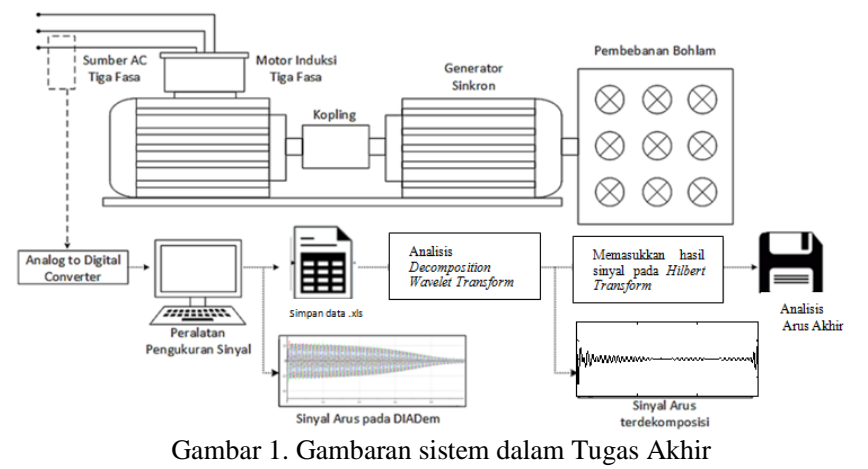

Pada Tugas Akhir ini digunakan motor induksi tiga-fasa dengan kapasitas sebesar 2HP atau setara dengan $1.492 \mathrm{~kW}$. Motor induksi disusun dengan koneksi bintang ( $\mathrm{Y}$ ) sehingga memiliki tegangan rating sebesar $\mathrm{V}_{\mathrm{t}}=380 \mathrm{~V}$ dan arus rating sebesar $\mathrm{I}_{\mathrm{L}}=3,44$ Ampere. Pembebanan mekanis yang digunakan pada pengujian ini berupa generator sinkron yang terkopel dengan motor. Kemudian generator sinkron dibebani elektris secara bervariasi dengan tiga jenis, yaitu 300, 600 dan 900 Watt. Pengambilan data dilakukan pada frekuensi sampling sebesar $5 \mathrm{kHz}$ dengan jumlah data 25.000 samples selama 5 sekon. Kemudian data yang dihasilkan disimpan dalam format file TDMS (Technical Data Management Streaming). Setelah data tersebut didapatkan, dilakukan pemotongan sinyal dengan software di Adem dan menghasilkan data sekitar 5000 samples selama 1 sekon. Data keluaran arus tersebut menjadi data masukan pada proses pengolahan sinyal berbasis decomposition wavelet transform dan Hilbert transform menggunakan software MATLAB.

\section{B. Pengkondisian Kerusakan Batang Rotor Motor Induksi}

Pengondisian kerusakan batang rotor pada motor induksi dilakukukan dengan memberikan kecacatan berupa lubang. Rekonstruksi kerusakan pada pengujian dilakukan dengan melubangi batatang rotor dengan mesin bor. Sistematis melubangi batang rotor pada motor induksi dengan cara bertahap yaitu 1BRB (Broken Rotor Bar) dengan kedalaman $3 \mathrm{~mm}$, 1BRB (Broken Rotor Bar) dengan kedalaman $7 \mathrm{~mm}$, 2BRB (Broken Rotor Bar) dengan kedalaman $7 \mathrm{~mm}$ dan $3 \mathrm{~mm}$, 2BRB (Broken Rotor Bar) dengan kedalaman $7 \mathrm{~mm}$ dan $7 \mathrm{~mm}$. 3BRB (Broken Rotor Bar) dengan kedalaman $7 \mathrm{~mm}, 7 \mathrm{~mm}$ dan $3 \mathrm{~mm}$. 3BRB (Broken Rotor Bar) dengan kedalaman $7 \mathrm{~mm}$, $7 \mathrm{~mm}$ dan $7 \mathrm{~mm}$. Pemilihan kedalaman dan diameter lubang pada batang rotor disesuaikan agar tidak merusak bagian laminasi dalam rotor. Pelubangan diberikan pada konduktor batang rotor dengan tujuan agar batang rotor tersebut patah.

Kondisi kerusakan bar pada batang rotor tersebut dapat dijelaskan dengan Gambar 2 berikut:

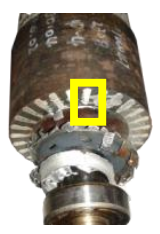

(a)

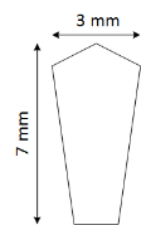




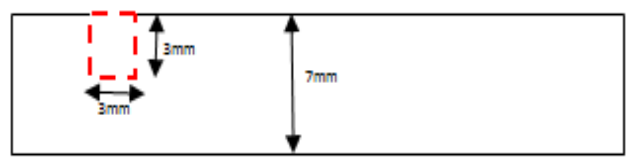

(b)

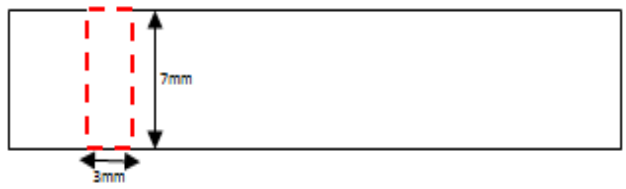

(c)

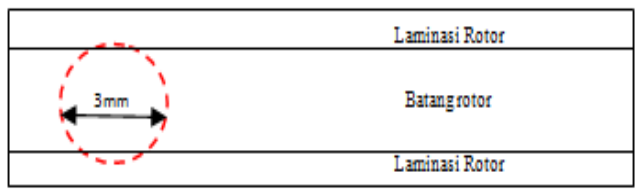

(d)

Gambar 2. (a) Bentuk penampang batang rotor. Bentuk pengkondisian kerusakan bar rotor tampak samping: (b) Kerusakan sedalam separuh dari kedalaman total, (c) Kerusakan sedalam kedalaman total, (d) Seluruh kerusakan berdiameter $3 \mathrm{~mm}$

\section{C.Pembebanan Mekanis dan Elektris}

Dalam Tugas Akhir ini, pembebanan mekanis yang digunakan adalah generator sinkron. Motor induksi dikopel dengan generator sinkron yang dibeban oleh rangkaian bola lampu dengan daya masing-masing sebesar 100 Watt. Pembebanan dengan lampu disebut dengan pembebanan elektris. Ketika motor induksi terkopel dengan generator dilakukan pembebanan dengan 4 tahapan, yaitu saat keadaan tanpa beban atau 0 Watt, 3 buah bohlam atau 300 Watt, 6 buah bohlam atau 600 Watt dan 9 buah bohlam atau 900 Watt.

\section{Akuisisi Data}

Pada Tugas Akhir ini A/D converter yang digunakan untuk data akuisisi adalah cDAQ-9171 dan NI 9215. Frekuesi sampling yang digunakan adalah $5 \mathrm{kHz}$, maka dalam satu sekon terdapat 5.000 data dengan periose $0,2 \mathrm{~ms}$. Sinyal arus mula akan di sample pada frekuensi $5.000 \mathrm{~Hz}$ yang kemudian diubah menjadi sinyal digital. Pengambilan data sinyal arus ini dilakukan selama 5 sekon, sehingga total jumlah data adalah 25.000 samples. Dari data sinyal arus tersebut, dilakukan pemotongan arus hingga diambil hanya bagian transiennya saja. Sinyal arus mula tersebut dipotong hingga waktu 1 detik, maka jumlah data adalah 5.000 samples. Adapun proses akuisisi data akan dijelaskan pada diagram berikut:

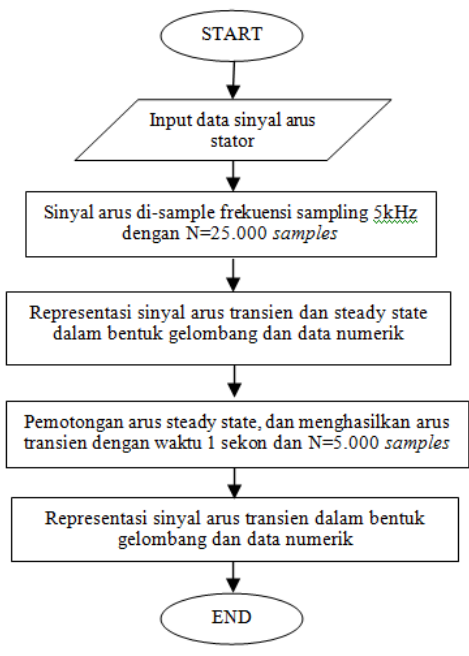

Gambar 3. Diagram alur akuisisi data

\section{E. Listing Decomposition Wavelet Transform}

Listing decomposition wavelet transform diperlukan untuk mengolah sinyal arus hasil pengukuran sehingga nantinya mampu dideteksi kondisi batang rotor pada motor induksi dalam keadaan sehat atau mengalami kerusakan. Secara garis besar proses pemecahan sinyal dengan menggunakan fungsi highpass dan lowpass filter, modifikasi sinyal berdasarkan fungsi skala dan waktu, rekonstruksi sinyal pada setiap level koefisiennya. Proses ini dinamakan dengan proses dekomposisi. Adapun spesifikasi dekomposisi yang digunakan adalah

Tabel 1.

Spesifikasi wavelet

\begin{tabular}{lrr}
\hline \hline & \\
\hline Jenis DWT & Spesifikasi DWT \\
Orde & Deubaches $(\mathrm{db})$ \\
Level Dekomposisi & 29 \\
Sampling frekuensi & 9 \\
\hline \hline
\end{tabular}




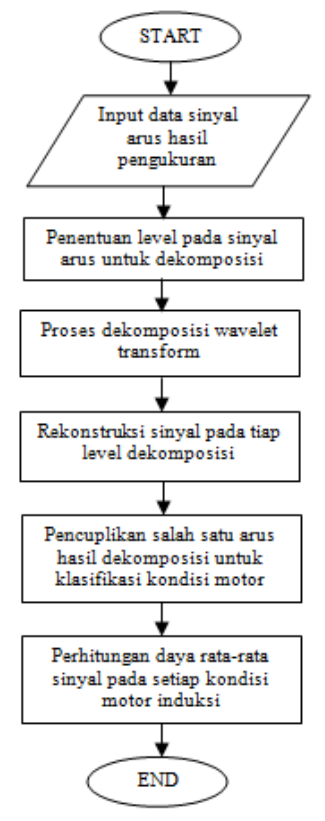

Gambar 4. Diagram alur Decomposition Wavelet Transform

\section{F. Listing Hilbert Transfrom}

Motode ini digunakan karena dapat melihat perbedaan pada kondisi rotor sehat maupun rusak dengan menggunakan sistem pendekatan titik-titik sinyal. Sinyal dari hasil dekomposisi tersebut, ditentukan nilai extrema dan diidentifikasi untuk mencari nilai local minima dan maxima. Kedua nilai tersebut kemudian diolah menggunakan interpolasi untuk mendapatkan bentuk upper envelope dan lower envelope. Hasil interpolasi merupakan pendekatan nilai asli untuk menghasilkan sinyal arus yang lebih sederhana. Sinyal sederhana ini digunakan untuk dapat mengklasifikasikan sinyal pada kondisi batang rotor motor induksi. Selanjutnya dilakukan analisis dengan melihat nilai puncak. Secara garis besar metode ini dapat dijelaskan dengan alur sebagai berikut :

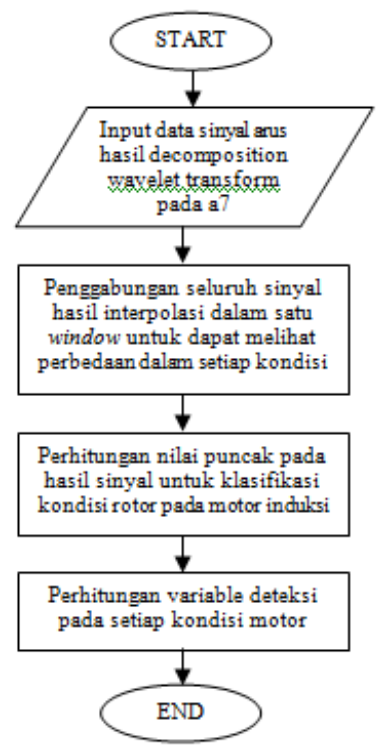

Gambar 5. Diagram alur Hilbert Transform

\section{Pengujian Sistem DeteKsi Kerusakan}

\section{A. Akuisisi Data}

Data yang diinginkan adalah data sinyal arus stator motor induksi dalam keadaan transien (starting) dengan frekuensi sampling 5kHz. Pemilihan frekuensi yang tinggi didasarkan oleh beberapa faktor, diantanya yaitu kapasitas motor lebih dari 1 HP sehingga dibutuhkan frekuensi sampling yang tinggu pula, dan semakin tinggi frekuensi sampling yang digunakan, maka resolusi akan semakin bagus. Berikut ini merupakan salah satu bentuk gelombang transien arus stator yang tersample.
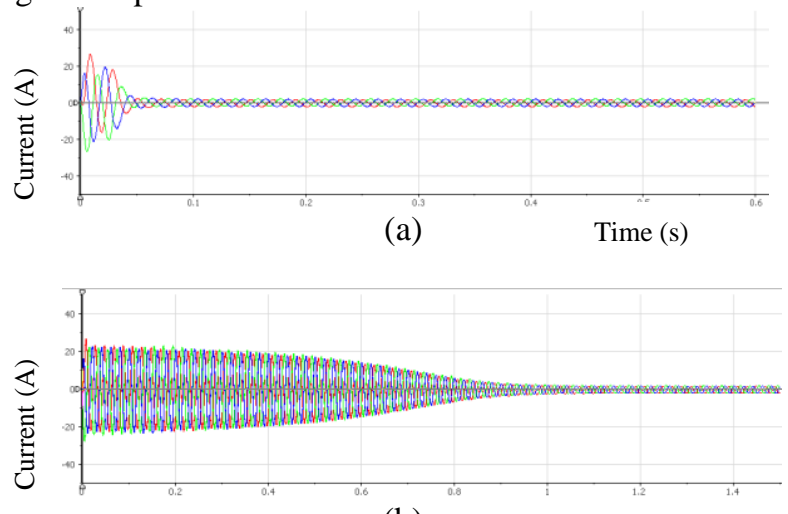

(b)

Time $(\mathrm{s})$

Gambar 6. Waveform sinyal arus stator. (a)Sinyal arus stator saat starting dengan kondisi tanpa beban (b) Sinyal arus stator saat starting dengan kondisi berbeban

\section{B. Pengolahan Sinyal Arus Stator ke dalam Bentuk Dekomposis Menggunakan Metode Wavelet}

Decomposition wavelet transform ini menguraikan sinyal arus utama menjadi beberapa model sesuai dengan level yang ditentukan. Level yang digunakan pada dekomposisi kali ini adalah level 7 dengan orde 29. Sedangkan jenis yang digunakan adalah deubaches (db). Berikut ini adalah hasil dekomposisi pada setiap kondisi.

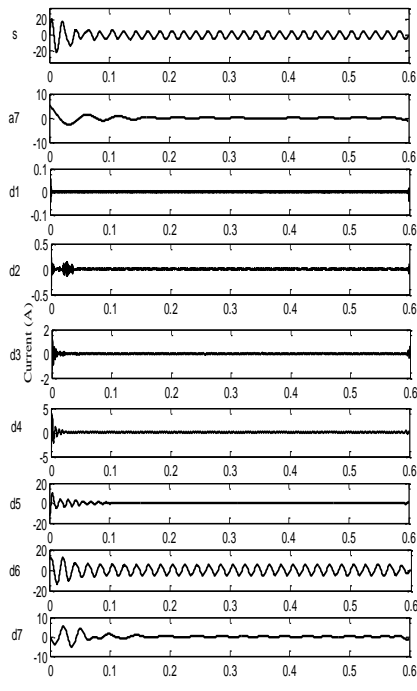

(a)

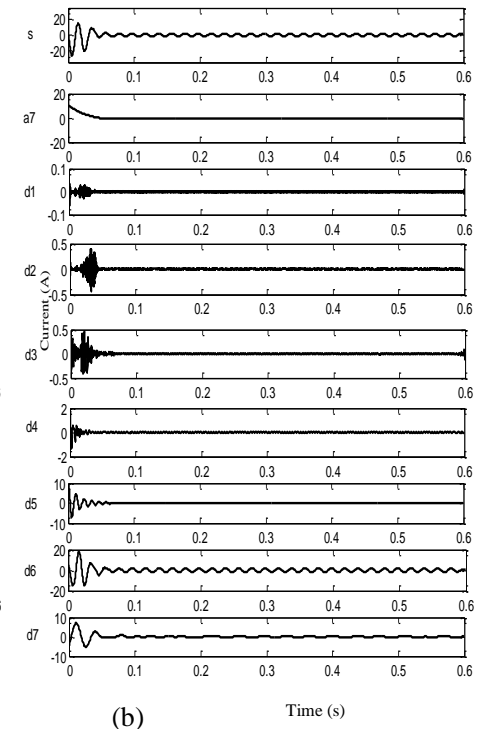

(b)
Gambar 7. Decomposition Wavelet Transform pada motor kondisi normal tanpa beban dan 3 Broken Rotor Bar (BRB) sedalam $7 \mathrm{~mm}, 7 \mathrm{~mm}$ dan $7 \mathrm{~mm}$ tanpa beban 


\section{Perumusan Variabel Deteksi Sinyal d7 pada Decomposition Wavelet Transform}

Pada tahap ini dilakukan pencuplikan salah satu sinyal arus hasil dari decomposition wavelet transform yang telah dijabarkan diatas. Pencuplikan diambil pada kondisi sinyal d7. Perbedaan pada setiap kondisi dapat dilakukan dengan melihat jumlah ripple yang dihasilkan pada setiap grafik. Kondisi yang akan diberikan tidak hanya dalam berupa kerusakan batang rotor pada motor induksi, namun pengaruh pembebanan akan disajikan pula pada pembahasan kali ini. Perhitungan daya rata-rata sinyal menggunakan rumus :

Daya rata-rata $\mathrm{d} 7=\sum_{0}^{\mathrm{n}} \mathrm{d}(\mathrm{t})^{2}$

dengan:

$n \quad$ : jumlah data $; \quad d(t)$ : nilai arus terhadap waktu

Berikut ini merupakan hasil pencuplikan sinyal pada d7 pada decomposition wavelet transform:

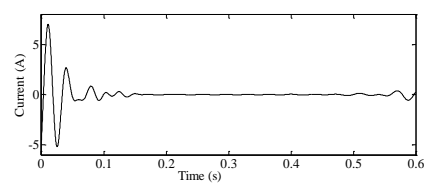

(a)

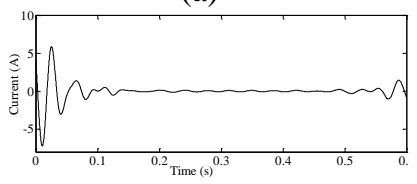

(c)

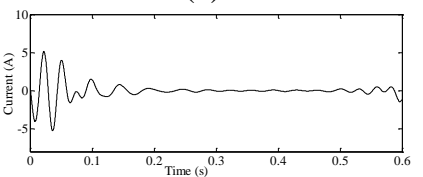

(e)

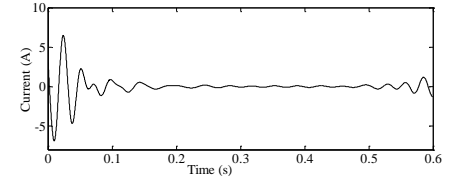

( $\mathrm{g})$

Gambar 7. Cuplikan sinyal d7 pada Decomposition Wavelet Transform saat tanpa beban. (a) Kondisi normal, (b) Kondisi 1BRB 3mm, (c) Kondisi 1BRB $7 \mathrm{~mm}$, (d) Kondisi 2BRB $7 \mathrm{~mm}$ dan 3mm, (e) Kondisi 2BRB $7 \mathrm{~mm}$ dan $7 \mathrm{~mm}$, (f) Kondisi 3BRB 7mm, 7mm dan 3mm, (g) Kondisi 3BRB 7mm, 7mm, dan

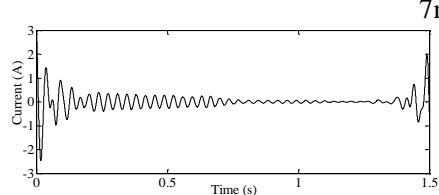

(a)

(c)

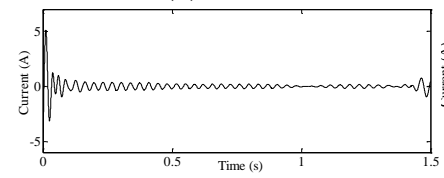

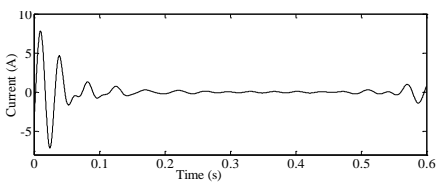

(b)

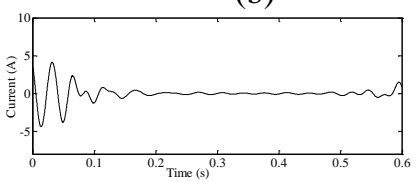

(d)

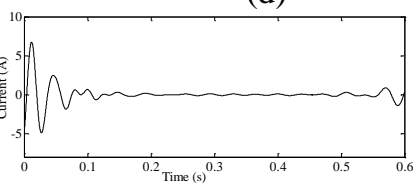

(f)

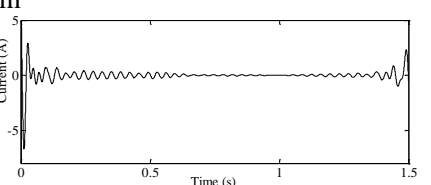

(b)

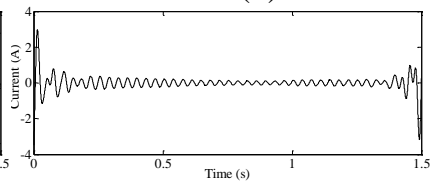

(d)

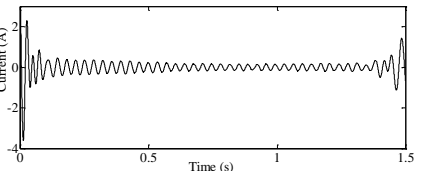

(e)

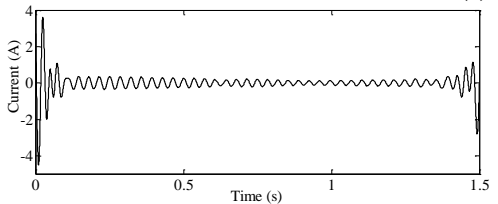

(g)

Gambar 8. Cuplikan sinyal d7 pada Decomposition Wavelet Transform saat full load. (a) Kondisi normal, (b) Kondisi 1BRB 3mm, (c) Kondisi 1BRB 7mm, (d) Kondisi 2BRB 7mm dan 3mm, (e) Kondisi 2BRB

$7 \mathrm{~mm}$ dan $7 \mathrm{~mm}$, (f) Kondisi 3BRB $7 \mathrm{~mm}, 7 \mathrm{~mm}$ dan $3 \mathrm{~mm}$, (g) Kondisi 3BRB $7 \mathrm{~mm}, 7 \mathrm{~mm}$, dan $7 \mathrm{~mm}$

Tabel 2.

Daya rata-rata sinyal dengan berbagai tingkatan beban

\begin{tabular}{cccccc}
\hline \hline \multirow{2}{*}{$\begin{array}{c}\text { Parameter } \\
\text { Kerusakan }\end{array}$} & \multicolumn{5}{c}{ DAYA INPUT } \\
\cline { 2 - 6 } & No Load & $\mathbf{9 0 0 W}$ & $\mathbf{1 . 1 0 0 W}$ & $\mathbf{1 . 3 0 0 W}$ & $\mathbf{1 . 5 0 0 W}$ \\
\hline Normal & 7.965 & 3.869 & 3.772 & 4.359 & 4.237 \\
$\mathbf{1 B R B}$ 3mm & 8.007 & 4.523 & 3.873 & 4.432 & 4.331 \\
$\mathbf{1 B R B} 7 \mathbf{m m}$ & 8.159 & 4.741 & 4.292 & 4.561 & 4.4 \\
2BRB 7 mm 3mm & 9.175 & 4.775 & 4.620 & 4.672 & 4.468 \\
2BRB 7 mm 7 mm & 9.782 & 4.903 & 4.926 & 5.131 & 4.651 \\
3BRB 7mm 7 mm & 9.869 & 5.497 & 5.474 & 5.203 & 4.813 \\
$\begin{array}{c}\mathbf{3 m m} \\
\text { 3BRB 7mm 7mm } \\
\mathbf{7 m m}\end{array}$ & 10.375 & 5.725 & 5.789 & 5.347 & 5.009 \\
\hline \hline
\end{tabular}

Berdasarkan sinyal yang dihasilkan pada gambar 7 dan 8 terdapat perubahan jumlah ripple antara batang rotor dalam kondisi normal dan batang rotor dalam kondisi rusak. Dapat dijelaska bahwa semakin dalam tingkat perlubangan rotor dan jumlah cacat lubang rotor atau dapat disebut semakin parah tingkat kerusakan batang rotor, maka jumlah ripple yang dihasilkan akan semakin tinggi pula. Namun, karna jumlah ripple tidak terlihat secara signifikan, maka dilakukan perhitungan daya rata-rata pada masing-masing grafik. Sama halnya dengan kondisi sebelumnya, nilai daya rata-rata yang dihitung berada pada range waktu 0-0.2 sekon.

\section{Pengolahan Sinyal Hasil Dekomposisi pada Sinyal}

Tahap akhir dari pengujian sistem deteksi kerusakan batang rotor pada motor induksi menggunakan metode hilbert transform, yaitu pencarian nilai puncak pada fungsi interpolasi. Pendekatan sinyal yang dilakukan adalah dengan mencuplik sinyal hasil decomposition wavelet transform. Hasil penyederhanaan sinyal pada sinyal a7 ini nantinya akan terlihat perbedaan nilai puncak pada masing-masing kondisi. Berikut ini bentuk penyederhanaan sinyal a7 menggunakan transformasi Hilbert:

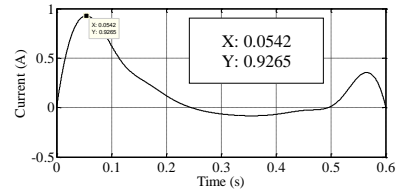

(a)

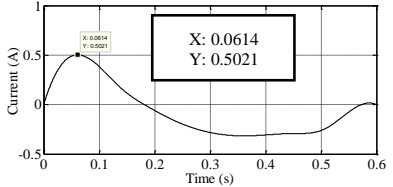

(b) 


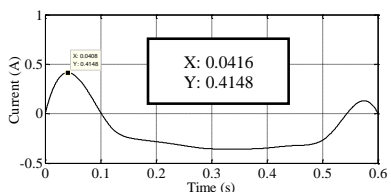

(c)

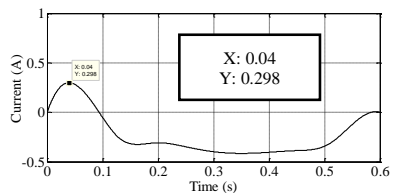

(e)

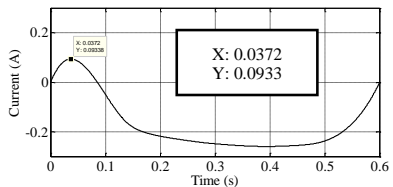

(g)

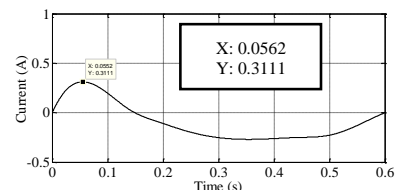

(d)

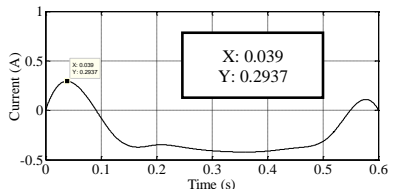

(f)

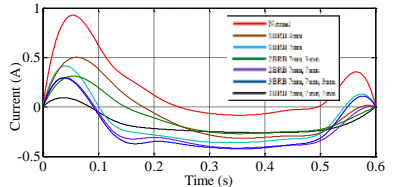

(h)
Gambar 9. Cuplikan penyederhanaan sinyal a7 saat tanpa beban. (a) Kondisi normal, (b)Kondisi 1BRB 3mm, (c) Kondisi 1BRB 7mm, (d) Kondisi 2BRB $7 \mathrm{~mm}$ dan 3mm, (e) Kondisi 2BRB 7mm dan 7mm, (f) Kondisi 3BRB 7mm, $7 \mathrm{~mm}$ dan 3mm, (g) Kondisi 3BRB 7mm, 7mm, dan 7mm, (h) Seluruh kondisi pada batang rotor dengan tanpa beban

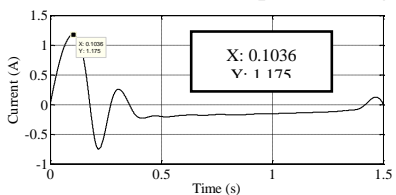

(a)

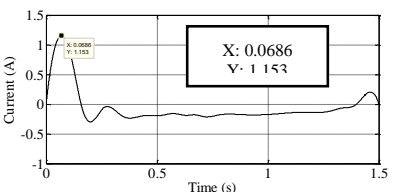

(c)

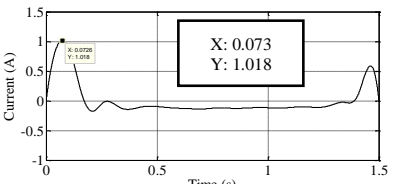

(e)

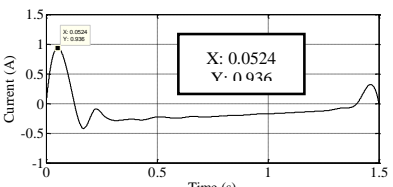

(g)

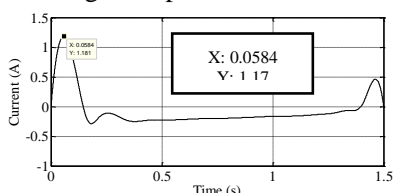

(b)

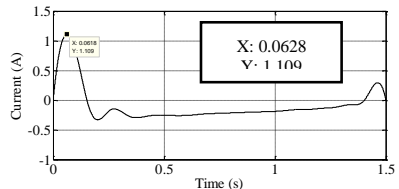

(d)

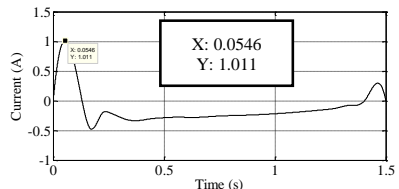

(f)

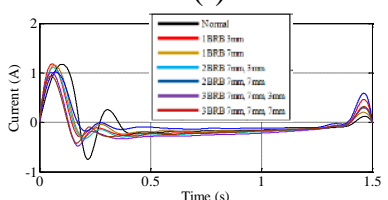

(h)
Gambar 10. Cuplikan penyederhanaan sinyal a7 saat full load. (a) Kondisi normal, (b)Kondisi 1BRB 3mm, (c) Kondisi 1BRB 7mm, (d) Kondisi 2BRB $7 \mathrm{~mm}$ dan $3 \mathrm{~mm}$, (e) Kondisi $2 \mathrm{BRB} 7 \mathrm{~mm}$ dan $7 \mathrm{~mm}$, (f) Kondisi 3BRB 7mm, $7 \mathrm{~mm}$ dan $3 \mathrm{~mm}$, (g) Kondisi 3BRB 7mm, 7mm, dan 7mm, (h) Seluruh kondisi pada batang rotor dengan tanpa beban

Tabel 3 .

Nilai puncak sinyal dengan berbagai tingkatan beban

\begin{tabular}{lrrrrr}
\hline \hline \multirow{2}{*}{$\begin{array}{l}\text { Parameter } \\
\text { Kerusakan }\end{array}$} & No Load & $\mathbf{9 0 0 W}$ & $\mathbf{1 . 1 0 0 W}$ & $\mathbf{1 . 3 0 0 W}$ & $\mathbf{1 . 5 0 0 W}$ \\
\cline { 2 - 6 } & & & & \\
\hline $\begin{array}{l}\text { Normal } \\
\mathbf{1 B R B}\end{array}$ & 0.9528 & 1.175 & 1.24 & 1.335 & 1.384 \\
$\mathbf{3 m m}$ & & & & & \\
$\mathbf{1 B R B}$ & 0.502 & 1.153 & 1.157 & 1.211 & 1.217 \\
$\mathbf{7 m m}$ & 0.4135 & 1.095 & 1.1012 & 1.109 & 1.138 \\
\hline \hline
\end{tabular}

\begin{tabular}{lccccc}
\hline \hline 2BRB & & & & & \\
7mm 3mm & 0.3111 & 1.056 & 1.089 & 1.093 & 1.095 \\
2BRB & & & & & \\
7mm 7mm & 0.298 & 0.9904 & 1.018 & 1.025 & 1.066 \\
3BRB & & & & & \\
7mm 7mm & & & & & \\
3mm & 0.2937 & 0.8828 & 0.9698 & 0.9991 & 1.011 \\
3BRB & & & & & \\
7mm 7mm & & & & & \\
7mm & 0.9339 & 0.7523 & 0.7524 & 0.936 & 0.9734 \\
\hline \hline
\end{tabular}

Pada hasil tabel 3 dapat terlihat, bahwa semakin parah kerusakan pada batang rotor motor induksi, maka nilai yang dihasilkan semakin rendah. Namun, pada level pembebanan yang diberikan nilai semakin tinggi. Pada metode ini dilakukan validasi data kembali dengan menggunakan rumus variabel deteksi. Rumus untuk mencari validasi deteksi adalah sebagai berikut:

$$
\begin{gathered}
\text { I RMS }=\sqrt{\frac{1}{\mathrm{n}} \sum_{0}^{\mathrm{n}} \mathrm{I}(\mathrm{t})}{ }^{2} \\
\mathrm{vd}=\frac{\mathrm{P}_{\mathrm{HT}}}{\mathrm{I}_{\text {RMS steadystat }}}
\end{gathered}
$$

dengan, vd: variabel deteksi, $\mathrm{I}_{\mathrm{RMS} \text { steady state }}$ : Arus RMS saat steady state, $\mathrm{n}$ : jumlah data, $\mathrm{I}(\mathrm{t})$ : nilai arus terhadap waktu, $\mathrm{P}_{\mathrm{HT}}$ : nilai puncak pada sinyal a7(puncak Hilbert Transform)

Pada variabel deteksi, yaitu tabel 4 dapat dilihat bahwa motor dikatakan mengalami kerusakan, bila nilai variabel deteksi $<0.4$

Tabel 4.

\begin{tabular}{|c|c|c|c|c|c|}
\hline \multirow{2}{*}{$\begin{array}{l}\text { Parameter } \\
\text { Kerusakan }\end{array}$} & \multicolumn{5}{|c|}{ DAYA INPUT } \\
\hline & No Load & $900 \mathrm{~W}$ & $1.100 \mathrm{~W}$ & $1.300 \mathrm{~W}$ & $1.500 \mathrm{~W}$ \\
\hline $\begin{array}{l}\text { Normal } \\
\text { 1BRB }\end{array}$ & 0.687 & 0.835 & 0.852 & 0.606 & 0.416 \\
\hline $\begin{array}{l}3 \mathrm{~mm} \\
\text { 1BRB }\end{array}$ & 0.152 & 0.351 & 0.357 & 0.361 & 0.338 \\
\hline $\begin{array}{l}7 \mathrm{~mm} \\
2 \mathrm{BRB}\end{array}$ & 0.125 & 0.317 & 0.323 & 0.269 & 0.279 \\
\hline $\begin{array}{l}7 \mathrm{~mm} \mathrm{3mm} \\
2 \mathrm{BRB}\end{array}$ & 0.094 & 0.305 & 0.314 & 0.254 & 0.201 \\
\hline $\begin{array}{l}7 \mathrm{~mm} \mathrm{7mm} \\
\text { 3BRB }\end{array}$ & 0.088 & 0.292 & 0.294 & 0.246 & 0.192 \\
\hline $\begin{array}{l}7 \mathrm{~mm} \mathrm{7mm} \\
3 \mathrm{~mm} \\
3 \mathrm{BRB} \\
7 \mathrm{~mm} 7 \mathrm{~mm}\end{array}$ & 0.087 & 0.259 & 0.279 & 0.22 & 0.175 \\
\hline $7 \mathrm{~mm}$ & 0.027 & 0.149 & 0.211 & 0.165 & 0.162 \\
\hline
\end{tabular}

Nilai variabel deteksi sinyal dengan berbagai tingkatan beban

\section{KESIMPULAN}

Berdasarkan hasil yang telah didapatkan dari proses pengujian dan analisis didapat kesimpulan bahwa Decomposition wavelet transform mampu mendeteksi kerusakan batang rotor pada motor induksi dengan mendekomposisi pada sinyal, kemudian menghitung daya rata-rata sinyal. Transformasi Hilbert dapat menggunakan penyederhanaan sinyal dari hasil dekomposisi, yaitu pada sinyal a7 dan dengan melihat puncak dari penyederhanaan sinyal tersebut. Pada motor dengan kondisi normal, nilai puncak yang dihasilkan lebih tinggi, sedangkan untuk motor 
yang mengalami kerusakan batang rotor memiliki nilai puncak yang cenderung semakin menurun. Pada hasil metode hilbert transform nilai puncak yang dihasilkan dihitung kembali nilai variabel deteksi maka dihasilkan bila nilai variabel deteksi menghasilkan nilai <0.4, maka dapat dikatakan batang rotor pada motor induksi mengalami kerusakan.Variasi level pembebanan pada arus mula (starting) tidak memengaruhi pendeteksian secara signifikan, namun dapat meningkatkan amplitudo arus stator motor.

\section{DAFTAR PUSTAKA}

[1] R. Valles-Novo, J. Rangel-Magdaleno, J. Ramirez-Cortes, H. PeregrinaBarreto, R. Morales-Carporal, "Empirical Mode Decomposition Analysis for Broken-Bar Detection on Squirrel Cage Induction Motors", IEEE Transactions on Instrumentation and Measurement, Desember, 2014.

[2] Ardhana, Nabila "Deteksi Kerusakan Batang Rotor pada Motor Induksi Sangkar Bajing Menggunakan Metode Standart Deviasi Berbasis Analisis Empirical Mode Decomposition”, Jurusan Teknik Elektro, Institut Teknologi Sepuluh Nopember Surabaya, Surabaya, Januari, 2016.

[3] Rabbani, Insan, "Deteksi Kerusakan Rotor Bar Motor Induksi Menggunakan Analisis Bi-spectrum, Jurusan Teknik Elektro, Institut Teknologi Sepuluh Nopember Surabaya, Surabaya, Juli, 2016.

[4] Swasetyasakti, Rifaldy, "Deteksi Kerusakan Rotor Bar Motor Induksi dengan Menggunakan Analisa Arus Keluaran Inverter berbasis Wavelet", Jurusan Teknik Elektro, Institut Teknologi Sepuluh Nopember Surabaya, Surabaya, Juli, 2013. 